University of Nebraska - Lincoln

DigitalCommons@University of Nebraska - Lincoln

January 2006

\title{
Puncturing ability of idealized canine teeth: edged and non-edged shanks
}

Patricia W. Freeman

University of Nebraska-Lincoln, pfreeman1@unl.edu

Cliff A. Lemen

University of Nebraska-Lincoln, clemen2@unl.edu

Follow this and additional works at: https://digitalcommons.unl.edu/natrespapers

Part of the Natural Resources and Conservation Commons

Freeman, Patricia W. and Lemen, Cliff A., "Puncturing ability of idealized canine teeth: edged and nonedged shanks" (2006). Papers in Natural Resources. 15.

https://digitalcommons.unl.edu/natrespapers/15

This Article is brought to you for free and open access by the Natural Resources, School of at DigitalCommons@University of Nebraska - Lincoln. It has been accepted for inclusion in Papers in Natural Resources by an authorized administrator of DigitalCommons@University of Nebraska - Lincoln. 


\title{
Puncturing ability of idealized canine teeth: edged and non-edged shanks
}

\author{
P. W. Freeman \& C. Lemen \\ School of Natural Resources and University of Nebraska State Museum, University of Nebraska-Lincoln, Lincoln, NE, USA
}

\section{Keywords:}

puncturing, indenters, canine teeth, odontology, crack propagation

\section{Correspondence:}

Patricia W. Freeman, School of Natural Resources, University of Nebraska-Lincoln, Lincoln, NE 68588-0514, USA.

Email: pfreeman1@unl.edu

Submitted March 2005; accepted 8 September 2005.

\begin{abstract}
Idealized edged and non-edged indenters, mimicking canine teeth, were used to puncture thin materials and thick materials. Less force was needed for the edged (triangular in cross section) indenter to penetrate thin Mylar, paper, leather, beetle elytra and turkey skin than the non-edged (circular in cross-section) indenter. Oak, grass and magnolia leaves responded equally to both indenters. In thick materials, the edged indenter punctured beetles, shrimp, bananas, and chicken flesh more easily than the non-edged indenter. Apple, tomato and avocado were punctured equally well. The edged indenter directs cracks at the corners so that the material can fold away in the direction of puncture, whereas cracks form unpredictably with the non-edged indenter. Edged indenters have the advantage in many of the materials tested.
\end{abstract}

\section{Introduction}

Freeman \& Weins (1997) and Evans \& Sanson (1998) found that the sharpness of a tooth's tip is critical to ease penetration into a material. However, these authors did not study what happened after initial penetration as the body, or shank, of the tooth penetrated deeper. Here we look at how cross-sectional shapes of the shanks of teeth, the part that lies below the tip, affect ease of penetration. Shanks of the canine teeth of many carnivores (Carnivora) are basically oval in cross-section (Van Valkenburgh \& Ruff, 1987). However, many of these carnivores have a sharp or even serrated edge running the length of the shank, particularly along the posterior surface. Extreme forms include sabertooth carnivores with blade-like canines. Freeman (1992) found that the cross-sections of bat (Chiroptera) canines vary greatly, often having complex shapes and sharp edges (Fig. 1). Beyond mammals, sharp edges on puncturing, canine-like teeth are also found in both sharks and dinosaurs. Hypotheses of the function of these sharp edges include easing the force needed to penetrate the food, increasing the ease of slicing food with lateral (sharks) or fore-aft (sabertooth) movement of tooth in food and directing crack propagation to other teeth to separate food cleanly with a bite (Freeman, 1992). Here we investigate the first of these hypotheses: whether edged teeth reduce the force of penetration. We use both round (conical) and edged (pyramidal) steel indenters as our teeth in a variety of substrates to measure ease of penetration.

It is obvious that a sharp tooth will penetrate a substrate more easily than a dull one (Freeman \& Weins, 1997; Ev- ans \& Sanson, 1998). Shergold \& Fleck (2004) have modeled the penetration of blunt and sharp indenters into soft solids. It also seems intuitive that an edged, blade-like tooth would slice through food more easily (Emerson \& Radinsky, 1980). Hence the idea that sabertooth carnivores may have sliced open the bellies of their prey by pulling their bladelike canines through the meat after penetration. But why should it be easier for an edged tooth to initially penetrate prey? To understand this problem, we find it useful to separate penetration into two actions: crack propagation and deformation. To form a crack, enough energy must be applied to break all the chemical bonds that once spanned the crack. If the strengths of the chemical bonds are known, we could predict the theoretical minimum amount of energy needed to break a substance across a cross-sectional area (work of fracture). It would be natural to think that the actual work of fracture for a material is closely tied to the strength of chemical bonds within it. This intuition proves to be incorrect (Gordon, 1978). The differences in strengths of chemical bonds among materials are modest when compared with the huge (a million-fold) differences in work of fracture between brittle and tough materials (e.g. glass and mild steel). More important to the work of fracture is the depth of molecular disturbance (deformation) produced around the crack. In a brittle substance, the depth of deformation is very shallow and most energy goes into breaking chemical bonds along the expanding crack. In ductile, tough material, much of the work of fracture goes toward deforming material at a considerable depth away from the crack. 
(a)

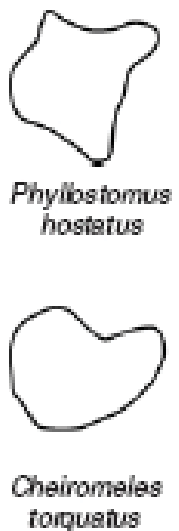

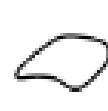

Centurio

senex

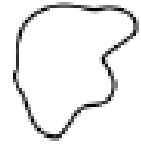

Noctilio

leporinus

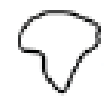

Eptesiaus

fuscus

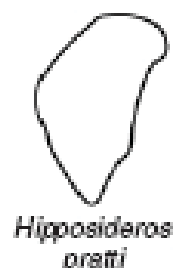

Anterio

t

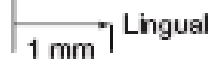

(b)
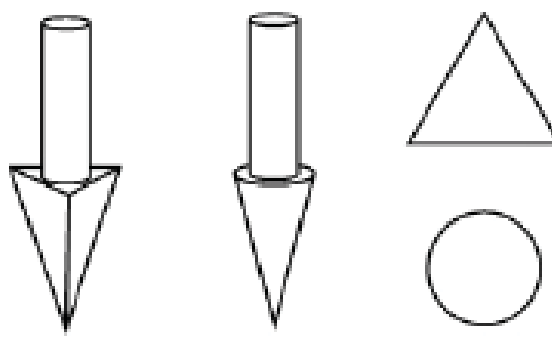

Figure 1 (a) Diversity of cross-sactional shapes of canine teeth in a sample of bats (Freernan 1992). (a) Model weth with edged or tfangubr shank and nonedged with corical shank and ther crosssactions.

We must consider the action of an edged indenter with this dichotomy of crack propagation and deformation in mind. In a tough material, a sharp edge will concentrate force onto a tiny zone of the material (Freeman, 1998). The edge breaks chemical bonds at the crack tip with a minimum of deformation away from the crack. Therefore, a sharp tool is useful in cutting through material. Breaking a stout rope is a good example. To break the rope by pulling at its ends would require considerable work. One can imagine the need for a tree and automobile. Much of the work done by the auto involves elastic (recoverable) and plastic (non-recoverable) deformation along the length of the rope and not simply breaking the chemical bonds at the site of parting. Contrast this work of fracture with the work needed to cut the rope with a razor-sharp knife. Far less work is needed with the knife, because a larger percentage of work is concentrated to break the chemical bonds rather than deform the rope.

Therefore, edged teeth should be at their best in a tough material. By tough we mean that the material resists crack propagation. Without a sharp edge, a tough material strongly resists the start and spread of cracks. Leather is a classic example of a tough material. A round indenter will not spread cracks easily through the leather. As this indenter penetrates, the leather both deforms and tears. In contrast, an edged indenter can concentrate force and direct the spread of a crack in leather as its edges penetrate it. In other words, it will cut the leather and will have a great advantage over a round indenter.

This line of reasoning is important to understand the action of round and edged indenters. The cutting action of the edge concentrates energy for efficient crack propagation (Freeman, 1998). For a thin blade, this is about all the energy needed. Only a slight expansion of the crack would allow passage of the thin body of the blade. In the case of the triangular, threeedged indenter used in this study, the material must be deformed away from the crack to allow passage of the bulkier triangular indenter. The amount of energy needed for this will vary with the rigidity of the material. In flexible material, the hole can be expanded easily by the material folding in the direction of penetration and away from the shank as the indenter cuts. In stiff material, a considerable amount of energy is needed to deform the material. A key point here is that if the substrate strongly resists folding back to allow passage of the shank, there may be less relative advantage for edged teeth.

Our indenters were not made to closely match any real canines. Using simple geometric shapes allowed us to control the indenter's size and shape more easily to quantify possible differences in function. One danger of this approach is that our edged indenters with triangular cross-section and very sharp edges may have advantages not enjoyed by real teeth with blunter-edged enamel. Further, the more complex shapes of real canines and serrated edges may have advantages that our steel indenters do not. However, as an initial effort to test tooth function, we feel justified in using this simple approach of ideal forms (Evans \& Sanson, 1998, 2003).

\section{Methods}

In this study, we use steel indenters with round (cone) and triangular cross-sections (a three-sided pyramid or tetrahedron supported by a pedestal). We made conical indenters with included angles of $29^{\circ}$. The edged indenter has dimensions of a height of $4.9 \mathrm{~mm}$ and a base of $3.4 \mathrm{~mm}$. We picked these dimensions so that round and edged indenters both have the same cross-sectional area and volume as a function of depth from tip. This similarity in area and volume produces indenters of the same size and allows us to compare round and edged shapes directly to find out whether there is an advantage to having edges.

We selected both thin and thick material to penetrate in this study. Thick and thin are defined relative to the height of the indenter. Material with a thickness much less than the height of the indenter is considered thin. Material thicker than the height of the indenter is considered thick. Indenter action changes between thick and thin substrates, and we handle these cases separately.

The thin materials used here include aluminized Mylar (thin plastic used for balloons and candy wrappers), goat leather, common office paper, insect cuticle (elytra of scarab beetle Polyphyla hammondi), oak Quercus ruber leaves, switch grass Panicum virgatum leaves, and the skin of a domestic turkey Meleagris gallopavo. The edges of the thin materials were secured before puncturing. Thick materials in- 
clude sculpey modeling clay, crisp apple (red delicious), ripe avocado, ripe banana, ripe tomato, shrimp, domestic chicken leg and three whole beetles, P. hammondi, Polyphyla hor$n i$ and Lucanus capreolus. The beetles were punctured dorsally through the elytra.

The force $(\mathrm{N})$ and depth $(\mathrm{mm})$ of penetration was measured with a uniaxial compression device, the In-Spec 2200 by Instron Corporation (Canton, MA, USA). The In-Spec 2200 was equipped with a $125 \mathrm{~N}$ load cell. Feed rate was set to $150 \mathrm{~mm}$ $\min 1$.

At least three replicates were made of each test. We used work as the measure of ease of passage (the area under the force to depth of penetration curve). We used the t-test to test for statistical difference in maximal force between indenter types in a material. Results were averaged to be presented graphically (Figs 3 and 4).

\section{Results}

The stress-strain curve is a conventional method that engineers use to test how a material will respond to a load. We use a similar method here to measure the action of the indenter's shank puncturing a material. In our case, we use a force (instead of stress) to depth of penetration. Engineers distinguish different parts of the stress/strain graph to characterize the properties of a material. Similarly we identify different parts on the curve to analyze the action of the indenter's shank.

Our approach can best be understood by referring to Fig. 2 and data from the penetration of Mylar by the round indenter. After the indenter touches the Mylar ('contact' in Fig. 2), the force increases as the tip presses down on the material before a hole is made. This force produces elastic and plastic deformation of the Mylar. When sufficient force is reached, the material fails and a small hole is created ('failure' in Fig. 2). Once the tip is through the Mylar, the shank enlarges the hole as the indenter is lowered. As penetration continues, the

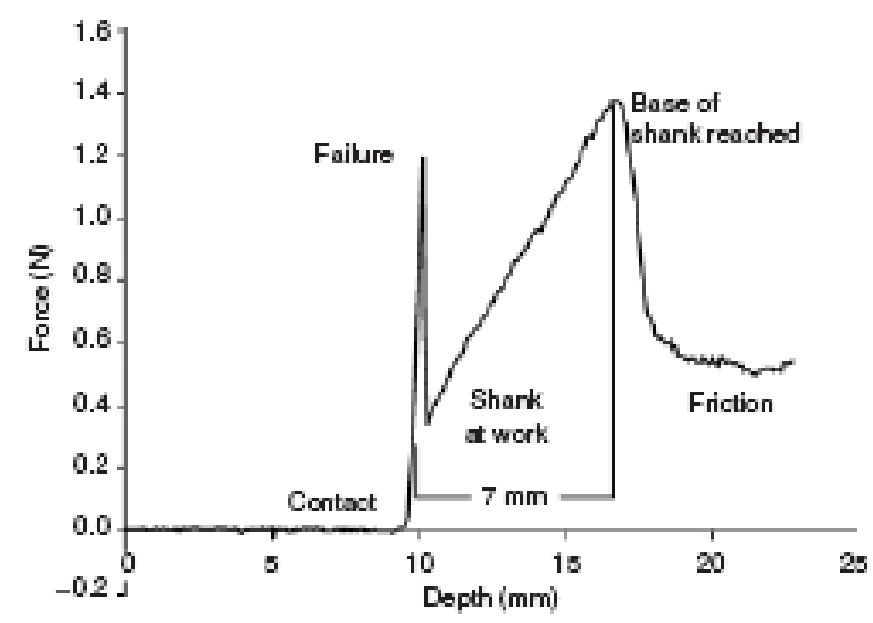

Figure 2 Results of a corical indemter puncturing alumirized Mylar plastic fim ilustrating the force needed to puncture and tien penetrate the pbstic. base of the indenter is reached and the hole is no longer being enlarged. The force beyond this point drops rapidly to reflect friction with the pedestal supporting the indenter. The peak of the force curve indicates the point when the base of the indenter reaches the Mylar (in this case, $7 \mathrm{~mm}$ ). The point where the shank first engages the Mylar can be found by subtraction. We set this depth to zero and plotted the action of the shank alone (Figs 3 and 4).

The relative advantage of an edged indenter puncturing thin material depends on the nature of the material being punctured. In the man-made materials studied here - leather, Mylar and paper - the relative advantage of the edged indenter to the round indenter varied from 10 times in leather to only two times in paper. In the biological materials studied, the advantage varied from a factor near 4 in beetle elytra and turkey skin to no advantage in oak and grass leaves (Fig. 3).

The advantages of edged indenters in thick material also varied. We found no advantage of edged indenters in penetrating apple, tomato and avocado. However, edged indenters did have an advantage in other substrates such as bananas, beetles, chicken flesh and shrimp (Fig. 4).

\section{Discussion}

Our goal was to find whether indenters with an edged shank take less force to penetrate than indenters with a round cross section. Results depend on the material being penetrated. First, the physical properties of the substrate are important. For brittle material such as glass, there is no value to edges because the indenter's tip shatters the substrate before the shank, edged or otherwise, engages. More subtle differences in materials such as paper and leather can vary in relative advantage of an edged indenter to round by a factor of 5 . Therefore, without tests of actual food items, it is not possible to predict the relative advantage of edged indenters and probably teeth as well. Mylar is a good example because it is fairly tough until a crack is started, and then the crack spreads with astonishingly little force. This quality makes it ideal as a candy wrapper. However, does our round indenter start and spread a crack as easily as greedy fingers after a snack? If so, there is little advantage for an edged indenter. On the other hand, the round cross-section of the indenter may blunt and slow the tip of the spreading crack that radiates from the initial puncture. This round indenter will spread the force more equally around its edgeless shank, increase the general deformation and in turn increase the work of penetration. In this case, the edged tool would be at an advantage. It turns out that Mylar does resist puncture by a round indenter much more than by an edged indenter by a factor of 4 (Fig. 3). Evidently the round indenter could not easily force a crack to spread in Mylar.

The result for Mylar contrasts with that for grass leaf. When either indenter penetrates the leaf, the tendency is for cracks to follow the edge of a vein. Both indenters keep the crack's tip sharp and the force concentrated at a small area. Once a crack starts along a vein, the leaf easily 'unzips' along 

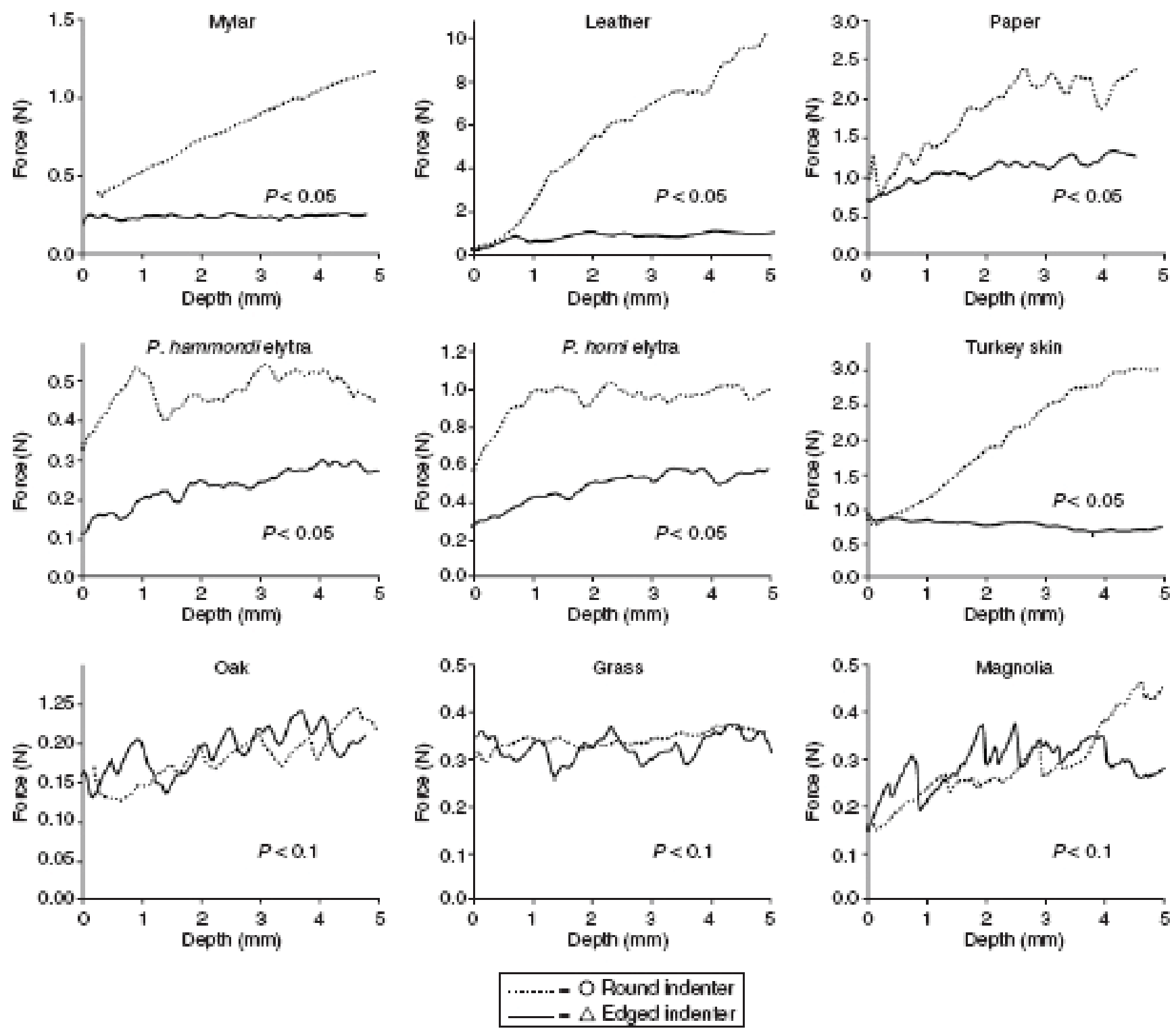

Fgure 3 Thin materials punctured by round and edged indenters. Round indenters need more fonce to puncture than edged inderters for Mylar, lesther, paper, skin of tukkey Mesesgris gailopavo and elytra of two beetles Polyphyis hammondi, Polyphyts homi of unequal toughess. No dfference in force is needed to punctume cak Ouercus ruber, grass Panicum virgatumand magnolia lesaves.

its length whether it is punctured by a round or edged indenter. Hence there is no advantage for the edged indenter.

The take-home message of the Mylar and grass examples is that, given the complex nature of materials that are punctured by teeth, experimentation is probably necessary to determine the importance of edges on the shanks of teeth.

Edged indenters lose most or all their advantage when penetrating certain thick substrates. We hypothesize that this loss of advantage occurs because in thick material the upper layers cannot fold out of the way as neatly as is possible under the thin model. The upper layers can move out of the way only by crushing into lower layers (e.g. apples) or spreading outward. Edged indenters do retain an advantage in many thick materials. We speculate that this can happen in a number of ways. First, if there is a tough, relatively thin external cover over a soft interior, the edges cut the outer layer during penetration and easily fold the tough layer into the soft inner core. Examples of this include tough exoskeletons of whole insects or shrimp.

A tough but highly ductile material is another type of substrate more easily pierced by an edged indenter. As vertebrate flesh is cut, it moves easily and laterally away from the indenter to allow easy passage. Without the cutting of tissue, the flesh remains in tension and more strongly resists the expansion of the hole. This advantage of edged indenters in vertebrate flesh and leather - two-ten times easier - suggests that 

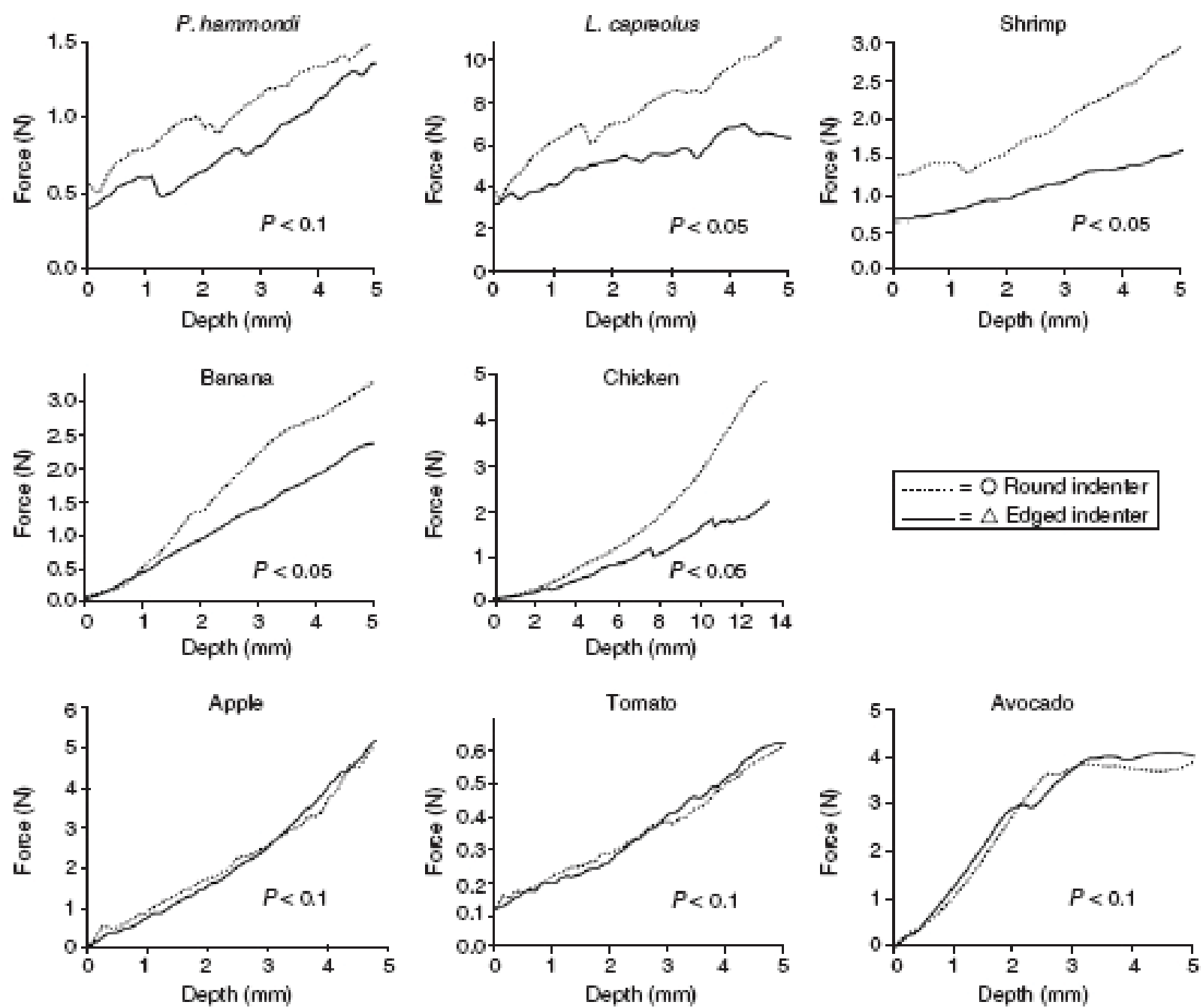

Figure 4 Thick materials punctured by round and edged indenters. Grester force is needed for round indenters to puncture whole beetes

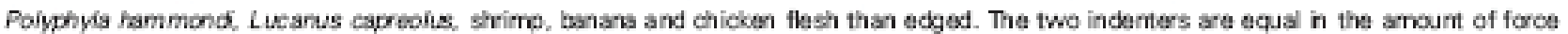
needed to puncture an apole, tomato and a vocado.

the function of the extreme, sharp edges in sabertooth carnivores could be to reduce the force needed to penetrate prey deeply and not just as cutting blades that are pulled through hide and meat.

\section{Conclusions}

Given the variation in our results, we conclude that material must be tested to assess the potential advantage of edged indenters. We find cases where the advantage is a factor of 10 but other cases of no advantage. We are forced to conclude that a general rule cannot be made about the utility of edges for easing the passage of teeth into food. Thus, while a rule can be made about the sharpness of a tooth's tip - the sharper the tooth, the easier the penetration - only a conditional rule based on food type can be made for edged teeth. Our result is a setback for creating general rules or first principles of tooth design and forces us to couch advantages in terms of specific food items.
Several future lines of enquiry need to be pursued to confirm and expand this conclusion. One interesting possibility is that large categories of food items will respond similarly to indenters. If so, generalities may be possible for insects or vertebrates and tooth shape. Another area untouched here is the interaction of several edged teeth in food. As an example in our study, the crisp apple showed no sign of cracking when penetrated by a single indenter. The result with opposing arcades of teeth biting into the apple might show different results, perhaps favoring edged teeth.

\section{Acknowledgements}

We thank the Institute of Natural Resources and Agriculture, the School of Natural Resources, and the University of Nebraska State Museum, University of Nebraska-Lincoln, for support and Angie Fox, Museum Technical Artist, for aid with the figures. 


\section{References}

Emerson, S.B. \& Radinsky, L. (1980). Functional analysis of sabertooth cranial morphology. Paleobiology 6, 295-312.

Evans, A.R. \& Sanson, G.D. (1998). The effect of tooth shape on the breakdown of insects. J. Zool. (Lond.) 246, 391-400.

Evans, A.R. \& Sanson, G.D. (2003). The tooth of perfection: functional and spatial constraints on mammalian tooth shape. Biol. J. Linn. Soc. 78, 173-191.

Freeman, P.W. (1992). Canine teeth of bats (Microchiroptera): size, shape, and role in crack propagation. Biol. J. Linn. Soc. 45, 97-115.

Freeman, P.W. (1998). Form, function, and evolution in the skulls and teeth of bats. In Bat biology and conservation: 140-156. Kunz, T.H. \& Racey, P.A. (Eds). Washington, D C: Smithsonian Institution Press.
Freeman, P.W. \& Weins, W.N. (1997). Puncturing ability of bat canine teeth: the tip. In Life among the muses: papers in honor of J. S. Findley. Special publication 3: 151-157. Yates, T.L., Gannon, W.L. \& Wilson, D.E. (Eds). Albuquerque, NM: Museum of Southwestern Biology.

Gordon, J.E. (1978). Structures or why things don't fall down. New York: Da Capo Press.

Shergold, O.A. \& Fleck, N.A. (2004). Mechanisms of deep penetration of soft solids, with application to the injection and wounding of skin. Proc. Roy. Soc., Lond. Ser. A 460, 3037-3058.

Van Valkenburgh, B. \& Ruff, C.B. (1987). Canine tooth strength and killing behaviour in large carnivores. J. Zool. (Lond.) 212, 379-397. 